\title{
Assessment of interhospital transport care for pediatric patients
}

\author{
Krittiya Chaichotjinda, MD, Marut Chantra, MD, Uthen Pandee, MD \\ Department of Pediatrics, Faculty of Medicine Ramathibodi Hospital, Mahidol University, Bangkok, Thailand
}

Background: Many critically ill patients require transfer to a higher-level hospital for complex medical care. Despite the publication of the American Academy of Pediatrics guidelines for pediatric interhospital transportation services and the establishment of many pediatric transport programs, adverse events during pediatric transport still occur.

Purpose: To determine the incidence of adverse events occurring during pediatric transport and explore their complications and risk factors.

Methods: This prospective observational study explored the adverse events that occurred during the interhospital transport of all pediatric patients referred to the pediatric intensive care unit of Ramathibodi Hospital between March 2016 and June 2017.

Results: There were 122 pediatric transports to the unit. Adverse events occurred in 25 cases (22\%). Physiologic deterioration occurred in 15 patients (60\%). Most issues (11 events) involved circulatory problems causing patient hypotension and poor tissue perfusion requiring fluid resuscitation or inotropic administration on arrival at the unit. Respiratory complications were the second most common cause (4 events). Equipmentrelated adverse events occurred in 5 patients (20\%). The common causes were accidental extubation and endotracheal tube displacement. Five patients had both physiologic deterioration and equipment-related adverse events. Regarding transport personnel, the group without complications more often had a physician escort than the group with complications (92\% vs. $76 \%$; relative risk, $2.4 ; P=0.028$ ).

Conclusion: The incidence of adverse events occurring during the transport of critically ill pediatric patients was $22 \%$. Most events involved physiological deterioration. Escort personnel maybe the key to preventing and appropriately monitoring complications occurring during transport.

Keywords: Interhospital transport, Pediatrics, Assessment

\section{Key message}

Question: The incidence and risk factor of the complication of pediatric transportation?

Finding: The incidence of adverse event during pediatric transportation were 22\%. Most events involved physiologic deterioration.

Meaning: Escort personnel maybe the key to preventing complication by appropriately monitoring and early intervention the complications occurring during transport.

\section{Introduction}

With difference levels of care among hospitals in developing countries, many critically ill patients presenting to a nontertiary care hospital need to be transferred to a tertiary hospital for more complex medical care. ${ }^{1-3)}$ Since 1986, the American Academy of Pediatrics (AAP) has stressed the roles of interhospital transportation plan into 4 aspects of transferal system: good communication between referral and receiving hospitals, appropriate personnel, suitable equipments, and appropriate monitoring. ${ }^{4)}$ Although several recommendations have been published ${ }^{5-7)}$ and many pediatric transport programs have been established, adverse events during patient transport still occur, with an incidence of $10 \%-20 \%$ in previous studies. $\left.{ }^{8,9}\right)$ The adverse events during patient transport, especially in pediatric patients, are poorly documented in Thailand. The primary objective of this study is to determine the incidence of complications occurring during pediatric patient transport. The secondary objectives are to explore the types of complication and risk factors.

\section{Methods}

We performed a prospective observational study at Ramathibodi Hospital, a tertiary-care university-based hospital in Bangkok, Thailand, which accepts critically ill patients from all over the country. All pediatric patients, age between 1 month to

\footnotetext{
Corresponding author: Uthen Pandee, MD. Department of Pediatrics, Faculty of Medicine Ramathibodi Hospital, Mahidol University, 270 Rama VI Road, Rachathevi, Bangkok, Thailand 
20 years, who were transferred from other hospital to an 8-bed pediatric intensive care unit (PICU) from March 2015 to June 2016 were included. When the patients arrived at the PICU, apart from a usual sign out, escorting physicians or nurses were asked to fill in the study record form and discuss about the condition of the patients and adverse events occurring during transport. Patient demographic data, patient status before transport, detail about transportation, and detail of significant adverse events occurring during transfer were collected. Final diagnosis, length of stay in the hospital, and other complications occurring in the first hour of arriving in PICU were obtained from medical records. Each patient was classified as "patient with complication" or "patient without complication" according to presence or absence of adverse events by consensus of the 2 investigators (CK and PU).

The adverse events were categorized into "physiologic deterioration" and "equipment-related complications". The physiologic deterioration includes: respiratory (respiratory failure or desaturation), circulatory (cardiac arrest, hypotension [systolic pressure $<70 \mathrm{mmHg}$ for an infant, $<70+[2 \times$ age $\{\mathrm{yr}\}] \mathrm{mmHg}$ for child $1-10$ years, $<90 \mathrm{mmHg}$ for child $>10$ years]), tachycardia (pulse rate $>220 /$ min for infant, $>180 /$ min for child), bradycardia (pulse rate $<80 / \mathrm{min}$ for infant, $<60 / \mathrm{min}$ for child), neurologic complication (altered mental status, seizure, hypothermia (temperature $<35^{\circ} \mathrm{C}$ ), and other metabolic problem such as hypoglycemia (blood glucose $<60 \mathrm{mg} / \mathrm{dL}$ ). The equipment-related complications include endotracheal (ET) tube displacement or obstruction, dislodge of intravenous line access, disconnected or inadequate oxygen supply, and inadequate batteries of any medical equipment. Risk factors between the 2 groups were analyzed.

This study was approved by the Institutional Review Board of Faculty of Medicine Ramathibodi Hospital, Mahidol University. (MURA2016/240, Protocol number: ID 04-59-03). The informed consent of patent were obtained from care giver when they arrived PICU.

Chi-square test was used for categorical variables and the Student $t$ test was used for continuous variables. All $P$ values $\leq 0.05$ were considered statistically significant. All statistical analyses were performed using SPSS ver. 17.0 (SPSS Inc., Chicago, IL, USA).

\section{Results}

During the study period, 112 pediatric patients were transferred to our PICU from 69 different referring hospitals. Patient characteristics and detail of transportation are shown in Table 1. The most common diagnoses were neurological disease (22\%), respiratory disease (17\%), hematologic or oncologic disease $(16 \%)$, and cardiac disease (14\%). All patients were transferred by ground ambulance (Table 1 ).

Adverse events during transport occurred in 25 out of 112 patients (22\%) as shown in Table 2.
The most common physiologic deterioration was circulatory complications (44\%). Two patients had neurological complications and one of them had serious complication needed immediate ET tube intubation. Equipment-related adverse events occurred in 10 patients (33\%). Both physiologic deterioration and equipment-related complication occurred in 5 patients. The first case was a 3-year-old girl with dilated cardiomyopathy who got accidental extubation during transport causing respiratory failure and required immediate reintubation on arrival at the PICU. The second case was an 8-month-old male infant with status epilepticus. ET tube displacement occurred during transport because of an inappropriate holding of the tube, also

Table 1. Patient characteristics and transportation details $(n=112)$

\begin{tabular}{|c|c|}
\hline Characteristic & No. (\%) \\
\hline \multicolumn{2}{|l|}{ Age } \\
\hline Infant ( $\leq 12 \mathrm{mo})$ & $33(30)$ \\
\hline Preschool (1-5 yr) & $30(27)$ \\
\hline School (5-10 yr) & $24(21)$ \\
\hline Adolescent (>10 yr) & $25(22)$ \\
\hline Male sex & $60(54)$ \\
\hline \multicolumn{2}{|l|}{ Diagnostic category } \\
\hline Neurological & $24(22)$ \\
\hline Respiratory & $19(17)$ \\
\hline Hematologic/oncologic & $18(16)$ \\
\hline Cardiac & $16(14)$ \\
\hline Gastrointestinal & $6(5)$ \\
\hline Genetic & $6(5)$ \\
\hline Toxicological & $6(5)$ \\
\hline Endocrine & $3(3)$ \\
\hline Renal & $3(3)$ \\
\hline Autoimmune & $2(2)$ \\
\hline Others & $9(8)$ \\
\hline Intubated before transport & $66(59)$ \\
\hline Vasoactive drugs & $23(21)$ \\
\hline \multicolumn{2}{|l|}{ Referring hospital } \\
\hline Government & $76(68)$ \\
\hline Primary & $4(4)$ \\
\hline Secondary (120-500 beds) & $28(25)$ \\
\hline Tertiary (>500 beds) & $39(35)$ \\
\hline Super-tertiary & $5(4)$ \\
\hline Private & $36(32)$ \\
\hline \multicolumn{2}{|l|}{ Arrival time period } \\
\hline Office hour (8 AM-4 PM) & $18(16)$ \\
\hline Nonoffice hour (4 PM-8 AM) & $94(84)$ \\
\hline \multicolumn{2}{|l|}{ Transport personnel } \\
\hline \multicolumn{2}{|l|}{ Physician } \\
\hline Pediatrician & $39(35)$ \\
\hline Emergency physician & $5(4)$ \\
\hline Neurosurgeon & $1(1)$ \\
\hline General Physician & $54(48)$ \\
\hline \multicolumn{2}{|l|}{ Nurse } \\
\hline Registration nurse & $10(9)$ \\
\hline Emergency nurse & $3(3)$ \\
\hline
\end{tabular}


causing desaturation and respiratory failure. After correction of the tube position at the PICU, his oxygen saturation returned to normal. The third case was a 13-year-old girl with end-state renal disease and volume overload. The furosemide infusion pump runs out of battery during transport causing high blood pressure in the patient. The fourth case was a 14-year-old boy with spastic cerebral palsy, tracheostomy status, and empyema thoracis. Oxygen supply was depleted during transport causing patient desaturation required immediate initiation of mechanical ventilator support on arrival at the unit. The last case was a 6year-old girl with enterocolitis and septic shock. She was hypotension and tachycardia due to disconnection of inotropic drug infusion line while she was transferred from an emergency medical service (EMS) stretcher to the PICU bed.

Adverse events categorized into aspects according to AAP quality of pediatric interhospital transportation are shown in Table 3. We found 3 cases which did not have adequate communication. From interviews with referring personnel, we noted

Table 2. Characteristics of adverse events in transported pediatric patients (total 25 cases, 30 events)

\begin{tabular}{ll}
\hline Adverse events & No. (\%) \\
\hline Physiologic deterioration & $15(60)$ \\
Respiratory & 1 \\
Desaturation/respiratory distress & \\
Circulatory & 11 \\
Hypotension/poor tissue perfusion & 9 \\
Hypertension & 2 \\
Neurological & 2 \\
Alteration of consciousness & 1 \\
Seizure & 1 \\
Metabolic & 1 \\
Hypoglycemia & \\
Equipment-related complications & $5(20)$ \\
ET tube displacement/accidental extubation & 1 \\
Loss of intravenous access & 2 \\
Depleted oxygen supply & 2 \\
Both physiologic deterioration and equipment-related complica- & $5(20)$ \\
tions & \\
Physiologic: respiratory failure/equipment: ET tube displace-- & 2 \\
ment & \\
Physiologic: respiratory failure/equipment: depleted oxygen & 1 \\
supply & \\
Physiologic: circulatory/equipment: depleted battery supply & 1 \\
Physiologic: circulatory/equipment: loss of intravenous access & 1 \\
\hline ET, endotracheal. &
\end{tabular}

Table 3. Adverse events categorized according to the American Academy of Pediatrics "Guidelines for Air and Ground Transportation of Pediatric Patients"

\begin{tabular}{lc}
\hline Standard transferring system & Adverse events (total 25 cases), $\mathrm{n}(\%)$ \\
\hline Communication & $3(12)$ \\
Personnel & $2(8)$ \\
Equipment & $9(36)$ \\
Monitoring & $1(4)$ \\
Deterioration of disease & $10(40)$ \\
\hline
\end{tabular}

that sometimes the physician who contacted and signed out to our critical care staffs and the escorting physician were not the same person. Some escorting personnel had never seen the patient before until referral time. One of the escorting nurses reported that she did not know whom she should to call for help (Table 3).

Transport personnel was all provided by referring to hospital and varied according to judgment of referring physician and available resources. Physicians accompanied their patients during transport in most of the cases (88\%) but were various in level of expertise; including general practitioners, emergency physicians, and pediatricians. Other transport personnel included nurses, emergency medical technicians, and nursing assistants. ET tube displacement happened in one case due to lack of skill in holding the tube of the general practitioners. Accidental extubation happened in another case which had general practitioner accompanied the patient and was the one who holds the ET tube.

Risk factors of adverse events, comparing between the 2 groups are shown in Table 4. The group of noncomplication had physician accompany more than the group with complication (92\% vs. 76\%; relative risk, $2.4 ; P=0.028$ ). Age, sex, underlying disease, and intubation status were not statistically different between the groups. The percentage of patients who received vasoactive drug infusion in the group with complication was almost 2 times more than in the group without complication but not statistically significant. Other risk factors such as referring hospital, transport distance, transport duration, hospital stay, and arrival time were also not statistically different between the groups (Table 4).

\section{Discussion}

Our study reports an incidence of adverse events occurring during transport of critically ill pediatric patients of $22 \%$, consistence with reports from previous studies (9\%-23\%; Table 5). 8 ,9)

Physiologic deterioration was the main adverse events in our study, account for more than half of all the events, whereas equipment-related complications account for one-third of the events. We found that $40 \%$ of adverse events occurred due to deterioration of diseases, which might be difficult to prevent, but $60 \%$ occurred due to ineffective communication, inappropriate escort personnel, inadequate equipment, and inappropriate monitoring which could be preventable.

\section{Communication}

Although communication between referring hospital staff and our PICU staff was made by phone in every case before transfer, we still found cases that adverse events could be prevented with better communication. When adverse events occurred during transfer, patients might not receive proper management due to lack of communication between escorting physician and pediatric critical care staffs. We recommend repeated phone calls 
Table 4. Risk of complications during transport of pediatric patients

\begin{tabular}{|c|c|c|c|}
\hline Variable & $\begin{array}{c}\text { Complication } \\
(n=25)\end{array}$ & $\begin{array}{c}\text { Without } \\
\text { complication } \\
(n=87)\end{array}$ & $P$ value \\
\hline Age (yr) & & & 0.22 \\
\hline Mean & 6.71 & 4.92 & \\
\hline Median (IQR) & $7.2(0.7-12.2)$ & $3.5(0.7-9.2)$ & \\
\hline Age & & & 0.199 \\
\hline Infant ( $\leq 12 \mathrm{mo})$ & $7(28)$ & $26(30)$ & \\
\hline Preschool (1-5 yr) & $3(12)$ & $27(31)$ & \\
\hline School (5-10 yr) & $7(28)$ & $17(19.5)$ & \\
\hline Adolescent (>10 yr) & $8(32)$ & $17(19.5)$ & \\
\hline Male sex & $13(52)$ & $47(54)$ & 0.86 \\
\hline Underlying disease & & & 0.50 \\
\hline Absence & $17(68)$ & $65(75)$ & \\
\hline Presence & $8(32)$ & $22(25)$ & \\
\hline Respiratory & 1 & 5 & \\
\hline Neurological & 3 & - & \\
\hline Cardiac & 2 & 6 & \\
\hline Hematologic/oncologic & 1 & 4 & \\
\hline $\mathrm{Gl}$ & - & 1 & \\
\hline Genetic & - & 5 & \\
\hline Others & 1 & 1 & 0.90 \\
\hline Intubated & $15(60)$ & $51(59)$ & 0.11 \\
\hline Vasoactive drugs & $8(32)$ & $15(17)$ & 0.34 \\
\hline \multicolumn{4}{|l|}{ Referring hospital } \\
\hline Government & $15(60)$ & $61(70)$ & \\
\hline Primary & 1 & 3 & \\
\hline Secondary (120-500 beds) & 9 & 19 & \\
\hline Tertiary (>500 beds) & 5 & 34 & \\
\hline Super-tertiary & - & 5 & \\
\hline Private & $10(40)$ & $26(30)$ & \\
\hline Transport distance (km) & & & 0.69 \\
\hline Mean & 112.6 & 129.4 & \\
\hline Median (IQR) & $46(28-85)$ & $46(28-142)$ & \\
\hline Transport duration (hr) & & & 0.82 \\
\hline Mean & 2.50 & 2.1 & \\
\hline Median (IQR) & $1.4(0.7-2.5)$ & $1.2(0.7-2.5)$ & \\
\hline Arrival time period & & & 0.76 \\
\hline Office hour (8 AM-4 PM) & $3(12)$ & $15(17)$ & \\
\hline Nonoffice hour (4 PM-8 AM) & $22(88)$ & $72(83)$ & \\
\hline Hospital stay (day) & & & 0.90 \\
\hline Mean & 19.6 & 20.7 & \\
\hline Median (IQR) & $13.5(6-22.5)$ & $15(6-30.5)$ & \\
\hline Transport personnel & & & 0.03 \\
\hline Physician & $19(76)$ & $80(92)$ & \\
\hline Nurse & $6(24)$ & $7(8)$ & \\
\hline Monitoring & & & 0.06 \\
\hline Vital signs & $24(96)$ & $85(98)$ & \\
\hline Oxygen & $24(96)$ & $85(98)$ & \\
\hline EKG & $16(64)$ & $71(82)$ & \\
\hline
\end{tabular}

Values are presented as number (\%) unless otherwise indicated. $I Q R$, interquartile range; EKG, electrocardiogram. with critical care staffs to consult when escorting personnel need help in stabilization patients.

\section{Personnel}

Our study shows that lack of physician during transport and level of expertise of the physicians may be risk factors of adverse events. Previous study found that transport by a specialized transfer team was associated with an odds ratio of mortality of 0.58 (95\% confidence interval, 0.39-0.87). ${ }^{7)}$ Such a team is not available in most of hospital in many countries including Thailand. Due to contract with the government during medical training, most medical student graduates in Thailand need to work as a general practitioner, referred to as an intern, at hospitals in rural area of the country before they could enter a higher medical training program. They usually are physician who accompanies the patient during transport to a tertiary-care hospital and act as a transport team leader.

The previous studies have shown that the educational structure of interhospital transport team has been the strong point for successful of transportation. ${ }^{10-13)}$ We suggest that the transport teams should be trained for core concepts in pediatric transport. The teams should be able to perform emergency procedure such as ET tube intubation, defibrillation, and cardiopulmonary resuscitation. To address this important issue, from the results of our study, the physician should be accompanied with the patients to solve the complication that maybe occurred during the transport. As the data from Table 4 shown that, if the physician escort with the patients the complication will less occurred $(P<0.03)$. We further analysis in physician accompany group (99 cases) confine to the age of patients weather less than 1 year or more than 1 year and detail of physician (pediatrician or nonpediatrician) in both complication (19 cases) group and noncomplication (80 cases) group. We found that no different in complication event in both complication group $(P=0.87)$ and noncomplication group $(P=0.84)$ respectively (Table 6).

\section{Equipment}

Most equipment failures in our study were related to ET tube

Table 5. Studies regarding complications during transport of pediatric patients

\begin{tabular}{|c|c|c|c|}
\hline Study & $\begin{array}{l}\text { No. of } \\
\text { pediatric } \\
\text { transfer } \\
\text { (cases) }\end{array}$ & $\begin{array}{l}\text { Adverse } \\
\text { events, } \\
\text { n (\%) }\end{array}$ & Outcome measurement \\
\hline $\begin{array}{l}\text { Kanter and Tompkins }{ }^{9)} \\
\text { (1989) }\end{array}$ & 117 & $22(18 \%)$ & $\begin{array}{l}\text {-Physiologic deterioration } \\
\text {-Equipment-related }\end{array}$ \\
\hline $\begin{array}{l}\text { Barry and Ralson }{ }^{8)} \\
\text { (1994) }\end{array}$ & 56 & $12(23 \%)$ & $\begin{array}{l}\text {-Major cardiorespiratory } \\
\text { compromise } \\
\text {-Serious adverse event }\end{array}$ \\
\hline Hatherill et al. ${ }^{1)}$ (2003) & 202 & $18(9 \%)$ & $\begin{array}{l}\text {-Critical adverse event } \\
\text {-Clinical adverse event }\end{array}$ \\
\hline $\begin{array}{l}\text { Limprayoon et al. }{ }^{3)} \\
\text { (2005) }\end{array}$ & 36 & $6(16 \%)$ & $\begin{array}{l}\text {-Clinical deterioration } \\
\text {-Equipment problem }\end{array}$ \\
\hline Our study (2017) & 112 & $25(22 \%)$ & $\begin{array}{l}\text {-Physiologic deterioration } \\
\text {-Equipment-related }\end{array}$ \\
\hline
\end{tabular}


Table 6. Physician escorts by group

\begin{tabular}{lccc}
\hline Physician accompany & $\begin{array}{c}\text { Age }<12 \\
\text { months }\end{array}$ & $\begin{array}{c}\text { Age }>12 \\
\text { months }\end{array}$ & $P$ value \\
\hline Complication group $(\mathrm{n}=19)$ & 2 & 5 & 0.87 \\
$\begin{array}{l}\text { Pediatrician } \\
\text { Nonpediatrician }\end{array}$ & 3 & 9 & \\
Noncomplication group $(\mathrm{n}=80)$ & & & 0.84 \\
Pediatrician & 10 & 22 & \\
$\quad$ Nonpediatrician & 14 & 34 & \\
\hline
\end{tabular}

displacement, loss of intravenous access, depletion of oxygen, and not enough battery supply of medical equipment. The previous study also addressed the issue of transport equipment that should well prepare and appropriate for each patient. ${ }^{14,15)}$ We emphasize on routine equipment checking before transportation to prevent the adverse events.

\section{Monitor}

Closed monitoring of the patient during transfer is the key for early detection and early intervention of complication during transportation. ${ }^{16)}$ One patient in our study was hypoglycemic, which could be prevented if we appropriately monitor bedside glucose during transport.

\section{Benefit of study}

The results of this study would be a useful information for developing a referral guideline to improve quality of pediatric transportation system in the future.

We report an incidence of adverse events occurring during transport of critically ill pediatric patients of $22 \%$. Most of the events were physiologic deterioration. The escort personal maybe the key person to prevent and appropriately monitor any complication during the transport. Referral guideline should be developed for improving quality of pediatric transportation system specifically for developing countries.

\section{Conflicts of interest}

No potential conflict of interest relevant to this article was reported.
See the commentary "Pediatric transport medicine: a yet unknown territory in Korea" via https://doi.org/10.3345/cep. 2019.01270.

\section{References}

1. Hatherill M, Waggie Z, Reynolds L, Argent A. Transport of critically ill children in a resource-limited setting. Intensive Care Med 2003;29:154754.

2. Droogh JM, Smit M, Absalom AR, Ligtenberg JJ, Zijlstra JG. Transferring the critically ill patient: are we there yet? Crit Care 2015;19:62.

3. Limprayoon K, Sonjaipanich S, Susiva C. Transportation of critically ill patient to Pediatric Intensive Care Unit, Siriraj Hospital. J Med Assoc Thai 2005;88 Suppl 8:S86-91.

4. American Academy of Pediatrics Committee on Hospital Care: Guidelines for Air and Ground Transportation of Pediatric Patients. Pediatrics 1986;78:943-50.

5. Orr RA, Felmet KA, Han Y, McCloskey KA, Dragotta MA, Bills DM, et al. Pediatric specialized transport teams are associated with improved outcomes. Pediatrics 2009;124:40-8.

6. Stroud MH, Trautman MS, Meyer K, Moss MM, Schwartz HP, Bigham MT, et al. Pediatric and neonatal interfacility transport: results from a national consensus conference. Pediatrics 2013;132:359-66.

7. Ramnarayan P, Thiru K, Parslow RC, Harrison DA, Draper ES, Rowan KM. Effect of specialist retrieval teams on outcomes in children admitted to paediatric intensive care units in England and Wales: a retrospective cohort study. Lancet 2010;376:698-704.

8. Barry PW, Ralston C. Adverse events occurring during interhospital transfer of the critically ill. Arch Dis Child 1994;71:8-11.

9. Kanter RK, Tompkins JM. Adverse events during interhospital transport: physiologic deterioration associated with pretransport severity of illness. Pediatrics 1989;84:43-8.

10. Giardino AP, Tran XG, King J, Giardino ER, Woodward GA, Durbin DR. A longitudinal view of resident education in pediatric emergency interhospital transport. Pediatr Emerg Care 2010;26:653-8.

11. Edge WE, Kanter RK, Weigle CG, Walsh RF. Reduction of morbidity in interhospital transport by specialized pediatric staff. Crit Care Med 1994; 22:1186-91.

12. Vos GD, Nissen AC, H M Nieman F, Meurs MMB, van Waardenburg DA, Ramsay G, et al. Comparison of interhospital pediatric intensive care transport accompanied by a referring specialist or a specialist retrieval team. Intensive Care Med 2004;30:302-8.

13. Britto J, Nadel S, Maconochie I, Levin M, Habibi P. Morbidity and severity of illness during interhospital transfer: impact of a specialised paediatric retrieval team. BMJ 1995;311:836-9.

14. Venkataraman ST, Rubenstein JS, Orr RA. Interhospital transport. A pediatric perspective. Crit Care Clin 1992;8:515-23.

15. Warren J, Fromm RE Jr, Orr RA, Rotello LC, Horst HM; American College of Critical Care Medicine. Guidelines for the inter- and intrahospital transport of critically ill patients. Crit Care Med 2004;32:25662.

16. Jouvet P, Lacroix J. Improving interhospital paediatric transport. Lancet 2010;376:660-1. 